for Chinese students to enroll at German, Austrian, Belgian, and Swiss universities. In addition to various antiplagiarism policies and procedures integrating the use of anti-plagiarism software programs like Turnitin or Unplag, faculty should present their assignments and expectations more clearly to the students, stipulating their cultural and educational backgrounds. This might be difficult to expect and demand from faculty, however: tenure-track faculty are under pressure to publish, and teaching seems to be less important for promotion; non-tenure-track faculty are under pressure to extend their contracts; and the administration is not likely to lose international students, who contribute an important part of the university's budget. Moreover, not everyone is ready to talk about such misconduct openly, because it might be perceived as racism. These improper dependencies might have dramatic consequences: It may be possible for less qualified people, or people with falsified diplomas, to get positions of responsibility, where their incompetence might lead to dangerous mistakes involving human lives. Universities should acknowledge this problem and allocate all necessary resources to mitigate academic misconduct involving students.

\section{Analyzing the Culture of Corruption in Indian Higher Education}

\section{William G. Tierney and Nidhi S. Sabharwal}

William G. Tierney is university professor, Wilbur-Kieffer professor of higher education, and codirector of the Pullias Center for Higher Education at the University of Southern California, US. He recently completed a Fulbright Fellowship to India.E-mail:wgtiern@usc.edu. Nidhi S. Sabharwal is associate professor in the Center for Policy Research in Higher Education at the National University of Educational Planning and Administration in New Delhi, India. E-mail: nidhis@nuepa.org.

A 11 universities have individuals who commit unacceptable acts. A student cheats on an exam. A professor fakes data in an experiment. A college president enriches himself by fraud. Although singular acts of corruption are unacceptable and must be condemned, they are individual errors of judgment that differ from systemic corruption. Systemic corruption occurs when the entire system is mired in schemes that are unethical and perpetrated at institutional and systemwide levels.

Many worry that India's postsecondary system is a post- er child for systemic corruption. India garnered worldwide attention when a cheating scandal, involving thousands of individuals who took medical examinations on behalf of students, was exposed. Answers for entrance tests to professional courses continue to be regularly leaked. Images of family members scaling walls to help their children cheat are etched in the nation's memory.

The problems are structural. Over a generation ago, the Indian government faced a dilemma: it wanted to dramatically increase the number of students attending postsecondary institutions, but it lacked adequate funding. Con-

\section{India garnered worldwide attention when a cheating scandal, involving thousands of individuals who took med- ical examinations on behalf of students, was exposed.}

sequently, private, nonprofit colleges became prominent. According to the Ministry of Human Resource Development, India has 35,357 higher-education institutions and 32.3 million students. 22 , I00 of the institutions are private colleges. Over 60 percent of private and public colleges have less than 500 students, and 20 percent have less than Ioo students. Although many say that the system is riddled with corruption, most are troubled by the 22,100 private colleges. The majority of news reports pertain to those with less than 500 students.

No one claims that all private institutions are corrupt; but large-scale surveys also will not yield data about dishonest practices. Who would admit on a survey that they engage in corruption? However, the sorts of activities that we discuss below are commonly acknowledged by those involved in higher education in India. Private institutions are, by law, nonprofit. Yet, the manner in which they are managed has enabled profit through "black money," or bribery. Private colleges enable multiple actors to generate incomes for themselves and others.

\section{DRIVERS OF CORRUPTION}

Agents: Students frequently do not approach a college directly, but go through "agents," or middlemen. Colleges also depend on agents so they can admit adequate numbers of students. The agents charge the students a commission for facilitating the admission process and negotiating a discount with the college principal. Agents also charge the col- 
lege a commission for supplying bulk admissions.

Students: Students pay for, and expect to earn a degree, but do not expect to attend classes. They often refer to themselves as "nonattending students." The institutions honor, so to speak, that expectation. The reasons for their nonattendance vary. The college may be located far from students' hometowns, or students may have work obligations. Students may appear when exams are given or do what is minimally required. Teachers, for example, e-mail lessons to students. Sometimes students come to the college if they are able, according to their own convenience. They take notes, show their work, take work home, and try to understand the lessons. The teachers then give them a final grade that will enable them to take the university examinations. The pass percentage in the college is mostly too percent.

Institutional Leaders: Institutional leaders often manipulate the system to maximize their financial gain. One strategy involves keeping teachers and the college principal "on paper" to meet the staffing norms set by the regulating authorities. Thus, teachers may be listed as full-time employees, but are actually not. A teacher gets a full salary on paper, but returns a substantial amount to the college. The institution's books appear to have a full complement of teachers, and the teachers receive an income for doing virtually nothing.

In addition, teachers and/or college principals may be involved in the university recruitment process, which creates revenue for the college and the recruiters. The "jaanpehchaan" (social network) system allows institutional leaders to access levers of opportunity and sustains their business interests. The principal may act like an agent by supplying students, taking a commission from students, and, in return, negotiating a lower admission fee and proxyattendance.

Visiting Committees: College management works hard to ensure that their institution complies with a plethora of regulations concerning daily management. When government-specified committees visit to rate, review, or rank the college, management rolls out the red carpet. Site-visit committees are paid an official amount. However, on visits to weak (or entirely nonexistent) institutions, members of the site committee might solicit more than ten times the official amount of the "shraddha" (a gratuity based on trust).

Colleges that do not exist are those without any buildings or that have a building, but it is empty. At times, inspection teams are taken to an entirely different building so they do not see an empty space. These colleges are able to function because of an exchange of money. That is, the institutions pay a significant amount of money to the authorities to gain the license to operate. Once they receive their initial permits, they then turn to paying visiting teams in order to provide a positive report.

\section{CONCLUSION}

The challenge in India, or for any country facing systemic corruption, is that a cultural ethos pervades individual actions. If a student cheats on an exam and the institution condemns cheating, the process of rectifying aberrant behavior is clear. However, reform is more difficult in a culture where "everyone does it." If black money is the norm rather than the exception, there is little incentive to change. The casual use of phrases such as "nonattending student" underscores a system that is rigged so that individuals can pay for degrees. When individuals get paid for no work-or receive payment for providing a particular score on a site visit or exam-corruption is endemic.

The first step in systemic reform is recognizing that a problem exists. India has a storied history of excellence in higher education. The world's first residential university was an Indian institution-Nalanda in the fifth century. India has generated eight Nobel Prize winners and a literary tradition that extends over thousands of years. To overcome the corruption that impairs confidence and quality, India's epic history should serve as an archetype for a postsecondary system that promotes research and workforce development. At the moment, the ethical base underpinning India's educational system is being eroded, undermining the very basis of mutual trust and educational standards.

\section{How Much Autonomy Do International Branch Campuses Really Have?}

\section{Megan Clifford and Kevin Kinser}

Megan Clifford is an independent consultant based in Oklahoma City, Oklahoma, US. E-mail: megan.e.clifford@gmail.com. Kevin Kinser is professor and head of the Department of Education Policy Studies at Pennsylvania State University, and codirector of the Cross-Border Education Research Team (C-BERT), US. E-mail: kpkg@psu.edu.

IHE regularly publishes contributions from C-BERT. See http://www.cbert.org.

T $n$ the past two decades, the governments of several devel1 oping nations including Qatar, the United Arab Emirates, and China have used public funds to support the establishment and on-going operation of international branch campuses (IBCs). They are not sponsoring IBCs to support a foreign institution's interest in internationalization, or to 